\title{
Desempenho, características de carcaça e composição óssea de suínos alimentados com diferentes níveis de ractopamina e fitase
}

\author{
Anderson Corassa ${ }^{1}$, Darci Clementino Lopes $^{2}$, Alexandre de Oliveira Teixeira ${ }^{3}$ \\ 1 Programa de Pós-Graduação em Zootecnia. UFV. \\ 2 Departamento de Zootecnia - UFV. \\ ${ }^{3}$ Assistente técnico - Bunge Fertilizantes.
}

RESUMO - O experimento foi conduzido com objetivo de avaliar o efeito da utilização de ractopamina e fitase em dietas para suínos no período final de terminação sobre o desempenho, as características de carcaça e a composição mineral no osso terceiro metacarpo. Foram utilizados 240 suínos machos castrados com peso inicial de 100,7 \pm 3,9 kg, em delineamento de blocos ao acaso, em arranjo fatorial $2 \times 3$, com dois níveis de ractopamina (5 ppm e 10 ppm) e três de fitase ( 0,500 e 750 uf), totalizando seis dietas, avaliadas em cinco repetições de oito animais por unidade experimental. O experimento teve duração de três semanas e, ao final, os animais foram abatidos para avaliação de carcaça. Não houve interação entre os níveis de ractopamina e fitase para nenhuma das variáveis. O peso corporal, o consumo diário de ração, a perda de peso durante o transporte, o percentual de carne magra e os teores de cinzas, fósforo e flúor no osso não foram influenciados pelas dietas. O nível de $10 \mathrm{ppm}$ de ractopamina foi o que promoveu melhores resultados de ganho de peso, conversão alimentar, peso de carcaça quente, carne magra total, índice de bonificação e teor de cálcio no osso. Os níveis de fitase avaliados não influenciaram o desempenho nem as características de carcaça, exceto o rendimento, que foi maior nos animais alimentados com a dieta contendo 500 uf em comparação àqueles que não receberam fitase. Dietas com 10 ppm de ractopamina proporcionam melhor desempenho e características de carcaça em comparação a dietas com 5 ppm. A substituição de fonte inorgânica por fitase (500 ou 750 uf) na dieta não influencia o desempenho, as características de carcaça nem a composição mineral no osso de suínos alimentados com dietas contendo ractopamina.

Palavras-chave: aditivos, $\beta$-adrenérgico, carcaça, enzima, fitato, osso

\section{Performance, carcass characteristics and bone composition of swines fed different levels of ractopamine and phytase}

\begin{abstract}
The experiment was carried out aiming at evaluate the effect of using ractopamine and phytase in diets for swines at the end of the finishing period on performance, carcass characteristics and mineral composition on the third metacarpus bone. It was used 240 barrows with initial weight $100.7 \pm 3.9 \mathrm{~kg}$ in a random block design, in a $2 \times 3$ factorial arrangement, with two levels of ractopamine (5 ppm and $10 \mathrm{ppm}$ ) and three levels of phytase (0, 500, and 750 FTU) totalizing six diets evaluated in five replications of eight animals per experimental unit. The experiment was conducted for three weeks and, at the end, the animals were slaughtered for carcass evaluation. There was no interaction among the levels of ractopamine and phytase for any of the variables. Body weight, ration daily intake, farm to slaughter shrink, percentage of fat-free lean and contents of ash, phosphorus and fluoride in the bone were not influenced by the diets. The level 10 ppm ractopamine promoted the best results of weight gain, feed conversion, hot carcass weight, total fat-free lean, payment index, and content of calcium in the bone. The evaluated levels of phytase did not influence neither the performance nor the characteristics of the carcass, except the yield, which was higher for the animals fed 500 FTU diet than those that did not receive phytase. Diets $10 \mathrm{ppm}$ ractopamine provided better performance and carcass characteristics than 5-ppm diets. Replacement of inorganic source by phytase (500 or 750 FTU) in the diet does not affect performance, characteristics of carcass neither mineral composition in the bone of swines fed diets with ractopamine.
\end{abstract}

Key Words: addictives, $\beta$-adrenergic, bone, carcass, enzyme, phytate

\section{Introdução}

O processo de avaliação da composição corporal de suínos ao abate desenvolvido pelas indústrias processadoras de carne suína permitiu premiar carcaças com maior teor de carne e estimulou o desenvolvimento de novas estratégias no campo da nutrição animal. Entre os aditivos, a inclusão de ractopamina em dietas de 
suínos em terminação tem apontado melhoria em índices de rendimento de carcaça, porcentagem de carne, ganho de peso e conversão alimentar (Armstrong et al., 2004; Pardo et al., 2004).

No entanto, tem sido observado que respostas ao uso desse aditivo variam em função de aspectos como nível de inclusão, duração de fornecimento e nutrientes na dieta, entre outros. Tem-se verificado que o desempenho dos animais melhora quando do uso de ractopamina em baixas concentrações enquanto as características de carcaça também melhoram em altas concentrações (Brumm et al., 2004; Crome et al., 1996). Nível de inclusão e tempo de fornecimento vêm sendo discutidos em função de respostas dependentes de estímulo e dessensibilização (Moody et al., 2000).

Por agir como repartidor de nutrientes e alterar o metabolismo animal, a ractopamina potencializa deposição proteica demandando teores maiores de nutrientes na dieta (Schinckel et al., 2001), entretanto respostas a distintas fontes de nutrientes foram pouco exploradas, em particular dos minerais.

Minerais como cálcio e fósforo em cereais apresentam-se complexados em estruturas como fitato e, assim, tornam-se parcialmente indisponíveis para animais monogástricos (Selle \& Ravindran, 2006). Logo, trabalhos compilados por esses pesquisadores têm comprovado a eficiência do uso da enzima exógena fitase como forma de redução do fitato como fator antinutricional. Além disso, essa enzima tem permitido o aumento da digestibilidade da dieta, diminuição da inclusão de fontes inorgânicas de cálcio e fósforo, diminuição dos custos das dietas (Maenz, 2001) e a diminuição do potencial poluente dos dejetos (Kornegay, 2001).

Dessa forma, entende-se como necessário avaliar os efeitos de diferentes níveis de ractopamina e da enzima fitase em dietas para suínos no período final de terminação sobre o desempenho, as características de carcaça e o teor de minerais em osso.

\section{Material e Métodos}

Conduziu-se um experimento em uma unidade de terminação de suínos no município de Bom Jesus, Santa Catarina, onde foram utilizados 240 suínos machos castrados, híbridos comerciais de alto potencial genético para deposição de carne magra, de única origem, com peso inicial de 100,7 $\pm 3,9 \mathrm{~kg}$, distribuídos em arranjo fatorial $2 \times 3$, sendo dois níveis de ractopamina (5 ppm e $10 \mathrm{ppm}$ ) e três níveis de fitase (0, 500 e 750 uf/kg de ração) (Tabela 1), contemplando seis tratamentos, com cinco repetições contendo oito animais por unidade experimental, totalizando quarenta animais por tratamento. O delineamento experimental utilizado foi de blocos casualizados, utilizando-se o peso corporal como critério para formação dos blocos.

As composições das dietas experimentais (Tabela 1) foram calculadas com base nas tabelas de composição nutricional de alimentos e exigências nutricionais para aves e suínos de Rostagno et al. (2005). Os níveis de proteína e aminoácidos foram ajustados para utilização da ractopamina segundo Schinckel et al. (2001). Estabeleceu-se a relação lisina:energia metabolizável (Lis:EM) de 3,0 g/Mcal de acordo com Apple et al. (2004), para otimizar desempenho sem desvantagem nas características de carcaça. Utilizou-se o coeficiente de digestibilidade de $88 \%$ para cálculo do valor de exigência de lisina digestível e a relação aminoácidos/lisina segundo Rostagno et al. (2005). A enzima utilizada é obtida a partir de Peniophora lycii, e foi incluída nas dietas para obtenção de 500 uf e 750 uf unidades de fitase e contribuição de 0,066 e 0,099\% de cálcio (Ca) e fósforo disponível (Pd) na dieta, respectivamente. Em função das inclusões da fitase nas dietas, a participação de fosfato bicálcico foi reduzida em 47 e $70 \%$ nas dietas contendo 500 e 750 uf, respectivamente.

Os animais foram alojados em galpão de alvenaria com piso de concreto e coberto com telhas de amianto. Cada unidade experimental foi constituída de uma baia $(3 \times 4,3 \mathrm{~m})$ contendo um bebedouro tipo chupeta, comedouro de madeira $(3 \times 0,30 \times 1 \mathrm{~m})$ disposto à frente da baia, representando $37,5 \mathrm{~cm}$ lineares por animal. A limpeza das baias foi realizada diariamente com raspagem dos dejetos e escoamento da lâmina d'água.

O registro diário de temperatura se fez por meio de dois termômetros de máxima e mínima, dispostos no corredor entre as baias. O controle de temperatura, ventilação e concentração de gases no interior do galpão foi realizado mediante o manejo de cortinas e microaspersão nas linhas dispostas sobre as baias. Água e ração foram fornecidos ad libitum durante todo o período experimental.

O experimento teve duração de 21 dias, como forma de observar a máxima resposta em desempenho, como sugerido por Williams et al. (1994) e Armstrong et al. (2004), que observaram queda nas respostas após esse período devido ao fenômeno chamado down-regulation ou dessensibilização dos receptores $\beta$-adrenérgicos (Moody et al., 2000).

Para avaliação do desempenho, foram utilizadas as variáveis: consumo de ração médio diário, ganho de peso médio diário e conversão alimentar a cada semana. Para mensuração desses parâmetros, foram realizadas pesagens 
Tabela 1 - Composição calculada das dietas experimentais

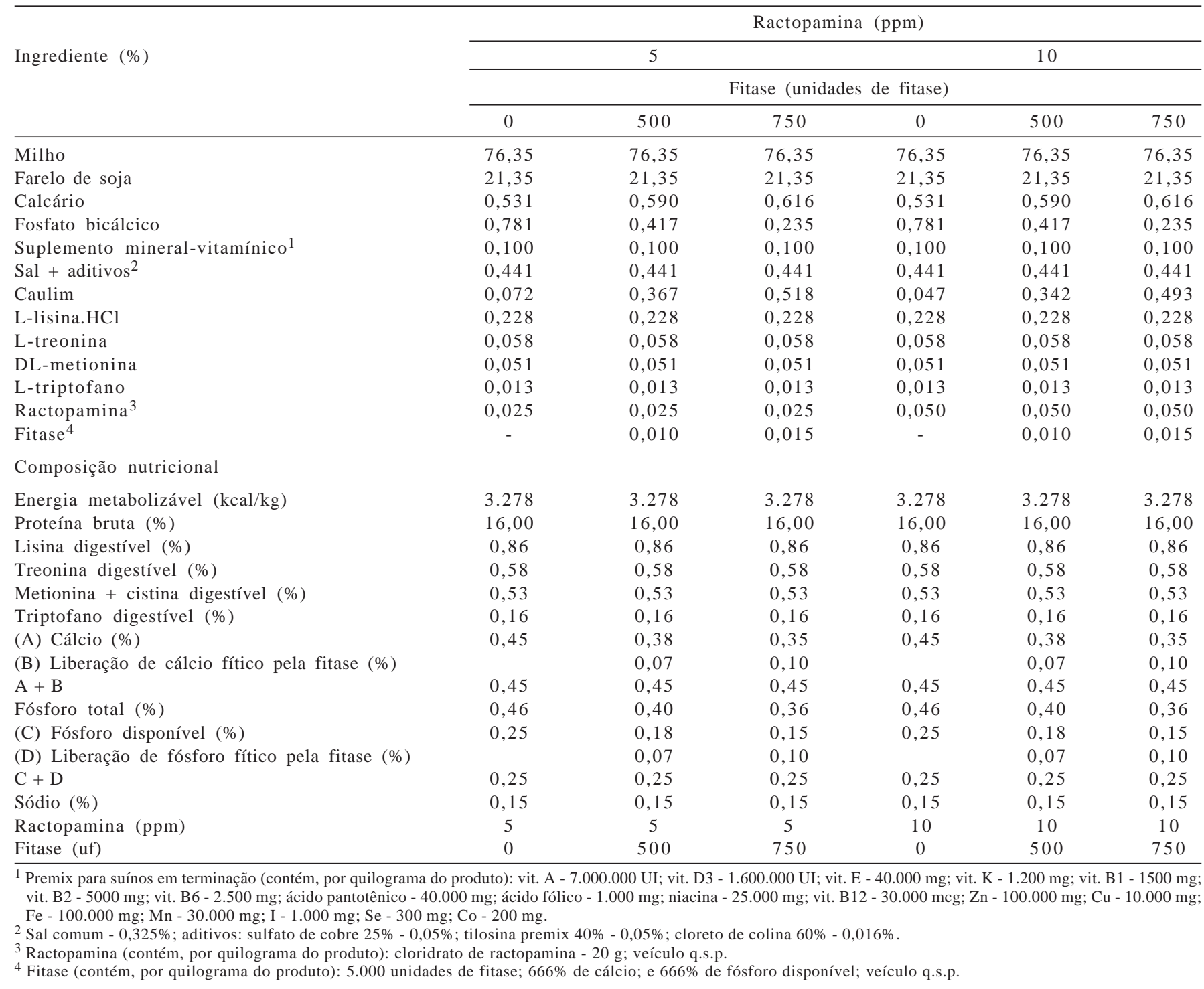

dos animais e sobras de ração no início do experimento e no

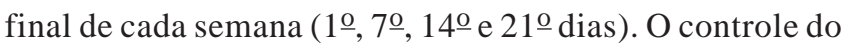
desperdício das rações foi feito diariamente. A conversão alimentar foi calculada pela relação do consumo com o ganho de peso.

Ao final do experimento, todos os animais foram identificados por meio de tatuagem e, em seguida, submetidos a jejum alimentar, mas não hídrico, de 12 horas para, no 22ํㅡ dia, serem transportados até o frigorífico. Os animais foram transportados por $417 \mathrm{~km}$ até o frigorífico, perfazendo o trajeto em aproximadamente seis horas. À chegada, por volta das $20 \mathrm{~h}$, os animais foram pesados novamente e permaneceram em jejum pré-abate até as $6 \mathrm{~h}$ do dia seguinte. Esses dados foram utilizados para cálculo da perda de peso dos animais em função do transporte.

Os animais foram insensibilizados, abatidos, depilados e eviscerados segundo procedimentos do frigorífico. As carcaças foram pesadas e passaram por avaliação de tipificação gerando os dados de porcentagem de carne magra e índice de bonificação, individualmente, a partir das medidas obtidas, com a pistola eletrônica, da espessura de toucinho e profundidade de músculo segundo Guidoni (2000). As variáveis rendimento de carcaça e carne magra total foram calculadas segundo Método Brasileiro de Classificação de Carcaças (ABCS, 1973): rendimento (\%) = peso de carcaça $(\mathrm{kg}) \div$ peso vivo (pré-abate, $\mathrm{kg}$ ); e carne magra total $(\mathrm{CMT}$, em $\mathrm{kg})=$ peso de carcaça $(\mathrm{kg}) \times$ carne magra $(\%)$.

Após o abate, extraiu-se o osso terceiro metacarpiano da pata anterior direita de um animal por repetição para determinação dos teores de cinza, cálcio, fósforo e flúor, segundo metodologia descrita por Teixeira et al. (2005).

Os dados experimentais foram submetidos à análise de variância e à comparação de médias, analisada pelo teste de Student-Newman-Keuls (SNK) a 5\% de probabilidade, para testar os tratamentos no esquema fatorial utilizando-se o programa SAEG (UFV, 1999). 


\section{Resultados e Discussão}

A temperatura mínima foi de $19,0 \pm 1,1^{\circ} \mathrm{C}$, a máxima, $30,4 \pm 2,4^{\circ} \mathrm{C}$ e a média $24,7 \pm 1,5^{\circ} \mathrm{C}$ durante o experimento.

Não houve interação $(\mathrm{P}<0,05)$ entre os níveis de ractopamina e fitase para nenhuma das características analisadas. O peso corporal dos animais e o consumo diário de ração não foram influenciados $(\mathrm{P}>0,05)$ pelas dietas em nenhum dos períodos avaliados (Tabela 2).

Igualdade estatística de peso dos animais ao final do experimento também foi observada por Armstrong et al. (2004) em pesquisa com dietas contendo 5 ppm ou 10 ppm aos 6, 13 ou 20 dias de fornecimento e Brumm et al. (2004), em animais de $81 \mathrm{~kg}$ a $107 \mathrm{~kg}$ alimentados com dietas contendo 0 ou $10 \mathrm{ppm}$ de ractopamina. Com níveis semelhantes de ractopamina, Main et al. (2001) avaliaram em 21 dias o efeito de 4,5; 6,75 e 9 ppm em suínos com peso inicial de 106 kg e também não registraram diferenças no peso final dos animais.

O consumo médio diário de ração não diferiu $(\mathrm{P}>0,05)$ entre os níveis de 5 ppm e 10 ppm de ractopamina, da mesma forma como registrado por Armstrong et al. (2004) e Xiao et al. (1999), que compararam uma dieta controle a outra com $20 \mathrm{ppm}$ de ractopamina. No entanto, isso diferente do estudo de Crome et al. (1996), que observaram diminuição do consumo de ração em função do aumento do nível de ractopamina na dieta.
Os maiores valores $(\mathrm{P}<0,05)$ de ganho médio diário foram obtidos com as dietas contendo maior nível de ractopamina no período de 7 a 14 dias e no período total. Esse efeito da melhora do ganho de peso ao final de 14 dias não foi observado na pesquisa de See et al. (2004), que não apontou diferença entre 5 ppm e 11,7 ppm nas variáveis de desempenho. Por outro lado, o ganho médio diário ao final dos 21 dias confirmaram as tendências apontadas por Crome et al. (1996) e Stites et al. (1991) de aumento no ganho médio diário com a inclusão crescente de ractopamina na dieta.

Nessa variável, a resposta não foi constante durante o período de fornecimento: apresentou pico na segunda semana de avaliação e, em seguida, uma resposta menos significativa. Essa constatação também foi registrada em trabalhos anteriores, nos quais o ganho de peso dos animais alcançou um pico e, em seguida, diminuiu durante o período de utilização da ractopamina (Kelly et al., 2003; Williams et al., 1994; Dunshea et al., 1993). Isso é uma possível manifestação do fenômeno conhecido como dessensibilização ou downregulation dos receptores adrenérgicos, como foi indicaram Moody et al. (2000). No entanto, o pico observado neste trabalho aconteceu antecipadamente em relação ao relatado por Williams et al. (1994).

Quanto à conversão alimentar, os animais alimentados com dietas contendo $10 \mathrm{ppm}$ de ractopamina apresentaram melhores valores $(\mathrm{P}<0,05)$ em todos os períodos, à exceção da terceira semana de avaliação. Essa constatação está de

Tabela 2 - Desempenho de suínos em terminação alimentados com dietas contendo ractopamina e fitase por período experimental

\begin{tabular}{|c|c|c|c|c|c|c|}
\hline \multirow[t]{2}{*}{ Item } & \multicolumn{2}{|c|}{ Ractopamina $(p p m)^{1}$} & \multicolumn{3}{|c|}{ Fitase (uf) ${ }^{2}$} & \multirow[b]{2}{*}{ CV (\%) } \\
\hline & 5 & 10 & 0 & 500 & 750 & \\
\hline & \multicolumn{6}{|c|}{ Peso corporal (kg) } \\
\hline Inicial & 100,78 & 100,54 & 100,29 & 101,11 & 100,57 & 1,06 \\
\hline 7 dias & 109,49 & 109,58 & 109,43 & 109,67 & 109,51 & 1,35 \\
\hline 14 dias & 118,45 & 119,51 & 119,01 & 119,42 & 118,49 & 1,23 \\
\hline \multirow[t]{2}{*}{21 dias } & 126,62 & 127,79 & 127,22 & 127,32 & 127,08 & 1,21 \\
\hline & \multicolumn{6}{|c|}{ Consumo de ração (g/dia) } \\
\hline 0 a 7 dias & 3525 & 3331 & 3521 & 3356 & 3406 & 8,55 \\
\hline 7 a 14 dias & 3965 & 4111 & 4101 & 4028 & 3985 & 5,07 \\
\hline 14 a 21 dias & 3695 & 3619 & 3617 & 3600 & 3754 & 8,50 \\
\hline \multirow[t]{2}{*}{0 a 21 dias } & 3728 & 3687 & 3746 & 3661 & 3715 & 4,85 \\
\hline & \multicolumn{6}{|c|}{ Ganho de peso (g/dia) } \\
\hline 0 a 7 dias & 1244 & 1292 & 1306 & 1222 & 1277 & 12,9 \\
\hline 7 a 14 dias & $1280 \mathrm{~b}$ & $1418 \mathrm{a}$ & 1369 & 1394 & 1283 & 7,80 \\
\hline 14 a 21 dias & 1168 & 1183 & 1172 & 1128 & 1227 & 12,0 \\
\hline \multirow[t]{2}{*}{0 a 21 dias } & $1231 b$ & $1298 \mathrm{a}$ & 1282 & 1248 & 1262 & 4,29 \\
\hline & \multicolumn{6}{|c|}{ Conversão alimentar (g/g) } \\
\hline 0 a 7 dias & $2,86 \mathrm{~b}$ & $2,60 \mathrm{a}$ & 2,73 & 2,77 & 2,69 & 11,6 \\
\hline 7 a 14 dias & $3,13 b$ & $2,92 \mathrm{a}$ & 3,04 & 2,91 & 3,13 & 8,13 \\
\hline 14 a 21 dias & 3,19 & 3,07 & 3,10 & 3,23 & 3,09 & 8,96 \\
\hline 0 a 21 dias & 3,03b & $2,84 \mathrm{a}$ & 2,93 & 2,94 & 2,94 & 4,56 \\
\hline
\end{tabular}

${ }^{1}$ Médias com letras diferentes na mesma linha representam diferença entre 5 ppm e 10 ppm de ractopamina (P<0,05) pelo teste $F$.

${ }^{2}$ Médias com letras diferentes na mesma linha representam diferença entre 0,500 e 750 unidades de fitase $(\mathrm{P}<0,05)$ pelo teste SNK. 
acordo com os trabalhos de Main et al. (2001), que registraram, após 21 dias de fornecimento, melhor eficiência alimentar dos animais alimentados com 9 ppm em comparação àqueles com 4,5 ppm e Crome et al. (1996), avaliando animais até $125 \mathrm{~kg}$. No entanto, tais registros diferem daqueles apresentados por Armstrong et al. (2004), que avaliaram dietas contendo $5 \mathrm{ppm}$ ou $10 \mathrm{ppm}$ aos 6,13 ou 20 dias de fornecimento e não encontraram efeito na eficiência alimentar.

Melhores respostas de ganho de peso e conversão alimentar ao utilizar maior nível de ractopamina encontradas no presente trabalho podem ser devidas ao peso mais elevado desses animais e do seu maior número de receptores $\beta$-adrenérgicos associados às fibras musculares, como sugerido por Moody et al. (2000) e Bergen et al. (1989). Também se pode considerar que quanto mais pesado o animal, pior é sua eficiência alimentar (Gu et al., 1991), logo o papel de agente repartidor com a inclusão de 10 ppm de ractopamina gerou respostas de magnitude superior em relação à inclusão de 5 ppm.

Não houve efeito $(\mathrm{P}>0,05)$ dos níveis de fitase em nenhuma das variáveis de desempenho. A capacidade de suínos alimentados com dietas contendo fitase exógena em manter o mesmo desempenho em relação a dietas com fonte inorgânica de fósforo também foi apontada por trabalhos anteriores (Ludke et al., 2002, 2000; Han et al., 1997; O'Quinn et al., 1997; Cromwell et al., 1995, 1993). De forma semelhante, Shelton et al. (2004) averiguaram que a adição de fitase reverteu os efeitos negativos das dietas com reduzidos níveis de cálcio e fósforo disponível. Assim, a redução da fonte de fósforo inorgânico e a consequente complementação dos níveis nutricionais pela liberação de cálcio e fósforo fíticos por meio da fitase em dietas com ractopamina manteve o desempenho dos animais com 500 ou 750 uf. Dessa forma, o uso de fitase em maior inclusão pode reduzir os custos das dietas, uma vez que disponibiliza nutrientes intrínsecos dos cereais, minimizando a complementação com fonte inorgânica, além de reduzir o impacto ambiental pela diminuição da excreção de elementos poluidores como o próprio fósforo, pela melhoria da digestibilidade das dietas (Seynaeve et al., 2000; O'Quinn et al., 1997; Simons et al., 1990).

Por outro lado, o presente trabalho não registrou tendência, como descrito por Pardo et al. (2004), de menor ganho de peso em dietas contendo ractopamina formuladas com fitase em relação àquela com fonte de fósforo inorgânico.

Peso pré-abate e perda de peso devido ao transporte não foram influenciados $(\mathrm{P}>0,05)$ pelos tratamentos (Tabela 3). O peso de carcaça quente, carne magra total e índice de bonificação apresentaram valores superiores $(\mathrm{P}<0,05)$ nos animais alimentados com dieta contendo 10 ppm de ractopamina (Tabela 3). Diferentemente desses resultados, See et al. (2004) não registraram diferenças nas características de carcaça entre distintos programas de fornecimento, com níveis constante (11,7 ppm), crescente (5, 10 e $20 \mathrm{ppm}$ ) ou decrescente (20, 10 e $5 \mathrm{ppm})$, ao final de 42 dias de fornecimento, apontando, assim, para diversidade de respostas da ractopamina em função dos níveis usados e do período de alimentação.

Dietas contendo $10 \mathrm{ppm}$ de ractopamina melhoraram $(\mathrm{P}<0,05)$ o peso de carcaça quente, o que está de acordo com as informações de Armstrong et al. (2004) e Crome et al. (1996). Não houve efeito ( $\mathrm{P}>0,05)$ dos níveis de ractopamina no percentual de carne magra e no rendimento de carcaça. Resultados similares de carne magra e rendimento de carcaça entre diferentes níveis de ractopamina encontrados nesse estudo também foram registrados por Armstrong et al. (2004), que compararam dietas com 5 ppm e 10 ppm, e Main et al. (2001), comparando 4,5 ppm 6,75 ppm e 9 ppm de ractopamina. Nesse sentido, Xiong et al. (2006) e Xiao et al. (1999) não apontaram diferenças para rendimento de carcaça, mesmo quando compararam 0 e 20 ppm de ractopamina.

Mesmo não havendo diferença $(\mathrm{P}>0,05)$ no percentual de carne magra, o maior valor numérico da dieta contendo

Tabela 3 - Peso pré-abate, perda no transporte, características de carcaças e índice de bonificação de suínos em função das dietas experimentais

\begin{tabular}{|c|c|c|c|c|c|c|}
\hline \multirow[t]{2}{*}{ Item } & \multicolumn{2}{|c|}{ Ractopamina $(\mathrm{ppm})^{1}$} & \multicolumn{3}{|c|}{ Fitase (uf) ${ }^{2}$} & \multirow[b]{2}{*}{ CV (\%) } \\
\hline & 5 & 10 & 0 & 500 & 750 & \\
\hline Peso pré-abate (kg) & 119,22 & 120,33 & 119,66 & 120,13 & 119,52 & 1,27 \\
\hline Perda no transporte (kg) & 7,41 & 7,46 & 7,56 & 7,19 & 7,56 & 7,82 \\
\hline Perda no transporte (\%) & 5,85 & 5,83 & 5,94 & 5,65 & 5,94 & 7,59 \\
\hline Peso carcaça quente (kg) & $87,53 b$ & $88,87 \mathrm{a}$ & 87,66 & 88,90 & 88,04 & 1,26 \\
\hline Carne magra (\%) & 51,60 & 53,03 & 51,82 & 52,26 & 52,86 & 3,90 \\
\hline Rendimento de carcaça (\%) & 73,41 & 73,85 & $73,25 b$ & $74,00 a$ & $73,65 a b$ & 0,78 \\
\hline Carne magra total (kg) & $45,17 b$ & $47,12 \mathrm{a}$ & 45,44 & 46,45 & 46,54 & 4,67 \\
\hline Índice de bonificação & $106,03 b$ & $108,25 a$ & 106,11 & 107,35 & 107,97 & 2,71 \\
\hline
\end{tabular}

${ }^{1}$ Médias com letras diferentes na mesma linha representam diferença $(P<0,05)$ entre 5 e 10 ppm de ractopamina pelo teste $\mathrm{F}$.

${ }^{2}$ Médias com letras diferentes na mesma linha representam diferença $(\mathrm{P}<0,05)$ entre 0,500 e 750 uf pelo teste SNK. 
$10 \mathrm{ppm}$ de ractopamina contribuiu, juntamente com o peso de carcaça quente, para valores superiores $(\mathrm{P}<0,05)$ de carne magra total. O mérito dessas carcaças refletiu também em melhor índice de bonificação $(\mathrm{P}<0,05)$ dos animais alimentados com maior nível de ractopamina (Tabela 3). Por definição, a bonificação é um fator percentual que é aplicado na equação de pagamento dos animais na forma decimal; assim, a carcaça pode ser penalizada ou premiada quanto ao preço original (Gomide et al., 2006). Cada ponto aumentado no índice de bonificação pode expressar diferenças marcantes no retorno econômico. Dessa forma, as respostas do presente trabalho confirmam aquelas levantadas por Schinckel et al. (2001) e Moody et al. (2000), de que maiores níveis desse $\beta$-adrenérgico, além de melhorar a eficiência da ração aumentam a valorização das características de carcaça dos sistemas de comercialização.

A única característica de carcaça que foi influenciada pela inclusão de fitase foi o rendimento de carcaça, que apresentou resposta superior $(\mathrm{P}<0,05)$ da dieta com 500 uf em relação ao controle. Essa constatação apresenta-se divergente da encontrada por Shelton et al. (2004), que, ao avaliarem uso de 500 uf, não apontaram diferenças nessa variável. Nas demais variáveis de carcaça, apesar dos valores numéricos superiores para as dietas contendo a enzima em comparação a controle, não houve efeito da fitase ( $\mathrm{P}>0,05)$, igualando, assim, índices de desempenho e qualidade de carcaça de animais alimentados com dietas contendo ractopamina e formuladas com 500 ou 750 uf e com fonte de fosfato inorgânico.

Os dados deste trabalho estão de acordo com registros anteriores de Shelton et al. (2003), que determinaram o efeito da fitase em suínos em crescimento, reduzindo níveis de cálcio e fósforo disponível em $0,10 \%$, não apontando efeito em desempenho, espessura de toicinho à $10^{\underline{a}}$ costela e área do músculo longissimus. Também O'Quinn et al. (1997) não registraram efeito em suínos em terminação alimentados à base de sorgo e farelo de soja para espessura de toucinho à $10^{\mathrm{a}} \mathrm{e}$ à última costela, área do músculo longissimus ou perda por gotejamento, quando fitase foi adicionada a 500 uf. Peter et al. (2001) avaliaram espessura de toucinho, profundidade de lombo e porcentagem de carne magra em carcaças de suínos alimentados com dietas com ou sem fósforo inorgânico e com 300 ou 500 uf dos 84 aos 123 kg, e não registraram diferença entre os tratamentos. Shelton et al. (2004), avaliando animais dos $22 \mathrm{~kg}$ aos $109 \mathrm{~kg}$, adicionaram $500 \mathrm{uf}$ em substituição a 0,10\% de cálcio e fósforo disponível, e apontaram não haver diferença em desempenho e em características como peso de carcaça quente, área de músculo longissimus, espessura de toicinho à $10^{\underline{a}}$ costela e comprimento de carcaça.

As dietas experimentais não influenciaram $(\mathrm{P}>0,05)$ os teores de cinzas, fósforo e flúor do osso terceiro metacarpo (Tabela 4). Ossos de animais alimentados com dietas contendo $10 \mathrm{ppm}$ de ractopamina apresentaram maior $(\mathrm{P}<0,05)$ teor de cálcio que aquele de animais com 5 ppm. Para os teores de cinzas, fósforo e flúor, não houve efeito $(\mathrm{P}>0,05)$ do nível de ractopamina na dieta, no entanto os valores foram numericamente maiores para $10 \mathrm{ppm}$.

A inclusão de 500 ou 750 uf de fitase não influenciou $(\mathrm{P}>0,05)$ os teores de minerais presentes nos ossos de suínos alimentados com ractopamina, respaldando a capacidade da enzima em dispor minerais utilizados na estrutura esquelética dos animais. Apesar de não apresentar diferença, os valores de flúor remetem a uma tendência numérica de diminuição de seu teor de maneira proporcional ao aumento de fitase na dieta, isso porque a presença desse mineral é característica de fontes inorgânicas e que apresentam variação em função da origem rochosa, como se observa nas tabelas de composição de alimentos publicadas por Rostagno et al. (2005).

Tabela 4 - Teor de cinzas, cálcio, fósforo e flúor do osso de suínos em terminação alimentados com dietas contendo ractopamina e fitase

\begin{tabular}{|c|c|c|c|c|c|c|}
\hline \multirow[t]{2}{*}{ Item } & \multicolumn{2}{|c|}{$\begin{array}{l}\text { Ractopamina } \\
\quad(\mathrm{ppm})^{1}\end{array}$} & \multicolumn{3}{|c|}{$\begin{array}{r}\text { Fitase } \\
(\mathrm{uf})^{2}\end{array}$} & \multirow[t]{2}{*}{ CV (\% } \\
\hline & 5 & 10 & 0 & 500 & 750 & \\
\hline Cinzas (\%) & 54,73 & 55,16 & 55,21 & 54,92 & 54,72 & 1,85 \\
\hline Cálcio (\%) & $19,45 b$ & $19,91 \mathrm{a}$ & 19,81 & 19,60 & 19,62 & 2,81 \\
\hline Fósforo (\%) & 9,86 & 9,95 & 9,88 & 9,95 & 9,87 & 1,80 \\
\hline Flúor (ppm) & 144,4 & 147,1 & 153,7 & 145,4 & 138,2 & 16,8 \\
\hline
\end{tabular}

${ }^{1}$ Médias com letras diferentes na mesma linha representam diferença $(\mathrm{P}<0,05)$ entre 5 ppm e $10 \mathrm{ppm}$ de ractopamina pelo teste $\mathrm{F}$.

${ }^{2}$ Médias com letras diferentes na mesma linha representam diferença $(P<0,05)$ entre 0,500 e 750 unidades de fitase pelo teste SNK.

\section{Conclusões}

Suínos em terminação alimentados com dieta contendo 10 ppm de ractopamina durante as três semanas que antecedem o abate apresentam melhores resultados de desempenho, características de carcaça e teor de cálcio no osso em comparação a suínos alimentados com dietas contendo 5 ppm. O fornecimento de 500 ou 750 uf em dietas contendo ractopamina mantém o desempenho, as características de carcaça e o teor de minerais no osso de suínos em terminação. 


\section{Agradecimentos}

À DSM do Brasil Ltda, pelo fornecimento da enzima fitase, e ao Conselho Nacional de Desenvolvimento Científico e Tecnológico (CNPq), pela concessão da bolsa de estudo.

\section{Referências}

APPLE, J.K.; MAXWELL, C.V.; BROWN, D.C. et al. Effects of dietary lysine and energy density on performance and carcass characteristics of finishing pigs fed ractopamine. Journal of Animal Science, v.82, p.3277-3287, 2004

ARMSTRONG, T.A.; IVERS, D.J.; WAGNER, J.R. et al. The effect of dietary ractopamine concentration and duration of feeding on growth performance, carcass characteristics and meat quality of finishing pigs. Journal of Animal Science, v.82, p.3245-3253, 2004.

ASSOCIAÇÃO BRASILEIRA DE CRIADORES DE SUÍNOS - ABCS. Método brasileiro de classificação de carcaças. Estrela: ABCS, 1973. 17p.

BERGEN, W.G.; JOHNSON, S.E.; SKJAERLUND, D.M. et al. Muscle protein metabolism in finishing pigs feed ractopamine. Journal of Animal Science, v.67, n.9, p.2255-2262, 1989.

BRUMM, M.C.; MILLER, P.S.; THALER, R.C. Response of barrows to space allocation and ractopamine. Journal of Animal Science, v.82, p.3373-3379, 2004.

CROME, P.K.; MCKEITH, F.K.; CARR, T.R. et al. Effect of ractopamine on growth performance, carcass composition and cutting yields of pigs slaughtered at 107 and 125 kilograms. Journal of Animal Science, v.74, p.709-716, 1996.

CROMWELL, G.L.; COFFEY, R.D.; MONEGUE, H.J. et al. Efficacy of low-activity, microbial phytase in improving the bioavailability of phosphorus in corn-soybean meal diets for pigs. Journal of Animal Science, v.73, p.449-456, 1995.

CROMWELL, G.L.; STAHLP, T.S.; COFFEY, R.D. et al. Efficacy of phytase in improving the bioavailability of phosphorus in soybean meal and corn-soybean meal diets for pig. Journal of Animal Science, v.71, p.1831-1840, 1993.

DUNSHEA, F.R.; KING, R.H.; CAMPBELL, R. et al. Interrelationships between sex and ractopamine on protein and lipid deposition in rapidly growing pigs. Journal of Animal Science, v.71, p.2919-2930, 1993.

GOMIDE, L.A.M.; RAMOS, E.M.; FONTES, P.R. Tecnologia de abate e tipificação de carcaças. Viçosa, MG: UFV, 2006. 370p.

GU, Y.; SCHINCKEL, A.P.; FORREST, J.C. et al. Effects of ractopamine, genotype, and growth phase on finishing performance and carcass value in swine: 1. Growth performance and carcass merit. Journal of Animal Science, v.69, p.2685-2693, 1991.

GUIDONI, A.L. Melhoria de processos para a tipificação e valorização de carcaças suínas no Brasil. In: CONFERENCIA VIRTUAL INTERNACIONAL SOBRE QUALIDADE DE CARNE SUINA, 1., 2000, Concórdia. Proceedings... Concórdia: Embrapa, 2000. 14p. Disponível em: <www.cnpsa. embrapa.br/down.php?tipo=publicacoes \&cod_publicacao=290>. Acesso em: 7/4/2006.

HAN, Y.M.; YANG, F.; ZHOU, A.G. et al. Supplemental phytases of microbial and cereal sources improve dietary phytate phosphorus utilization by pigs from weaning through finishing. Journal of Animal Science, v.75, p.1017-1025, 1997.

LUDKE, M.C.M.M.; LÓPEZ, J.; LUDKE, J.V. et al. Utilização da fitase em dietas com ou sem farelo de arroz desengordurado para suínos em crescimento/terminação. Revista Brasileira de Zootecnia, v.31, n.5, p.2002-2010, 2002.
LUDKE, M.C.M.M.; LÓPEZ, J.; NICOLAIEWSKY, S. Efeito da fitase em dietas com ou sem fosfato inorgânico para suínos em crescimento. Revista Brasileira de Zootecnia, v.29, n.2, p.485-494, 2000.

MAENZ, D.D. Enzymatic characteristics of phytases as they relate to their use in animal feeds. In: BEDFORD, M.R.; PARTRIDGE, G.G. (Eds.) Enzymes in farm animal nutrition. Wallingford: CAB International. 2001. p.61-84.

MAIN, R.G.; DRITZ, S.S.; TOKACH, M.D. et al. Effects of feeding graded levels of ractopamine (paylean) on pig performance in a commercial finishing facility. Kansas State University. Swine Day 2001. p.74-76.

MOODY, D.E.; HANCOCK, D.L.; ANDERSON, D.B. Phenethanolamine repartitioning agents. In: D'MELLO, J.P.F. (Ed.) Farm animal metabolism and nutrition. New York: CAB International, 2000. p.65-95.

KELLY, J.A.; TOKACH, M.D.; DRITZ, S.S. Weekly growth and carcass response to feeding ractopamine (Paylean). In: AMERICAN ASSOCIATION OF SWINE VETERINARY, Perry, IA. 2003. Proceedings... Perry, 2003. p.51-58.

KORNEGAY, E.T. Digestion of phosphorus and other nutrients: the role of phytases and factors influencing their activity. In: BEDFORD, M.R.; PARTRIDGE, G.G. (Eds.) Enzymes in farm animal nutrition. Wallingford: CAB International, 2001. p. 237-271.

O'QUINN, P.R.; KNABE, D.A.; GREGG, E.J. Efficacy of Natuphos in sorghum-based diets of finishing swine. Journal of Animal Science, v.75, p.1299-1307, 1997.

PARDO, C.E.; KANE, J.A.; GLENN, M.E. et al. Growth and carcass traits of finishing pigs fed Paylean were not compromised by diet formulations based on phytase. Journal of Animal Science, v.82, p.77, suppl.2, 2004 (Abstract).

ROSTAGNO, H.S.; ALBINO, L.F.T.; DONZELE, J.L. et al. Tabelas Brasileiras para aves e suínos. Composição de alimentos e exigências nutricionais. 2.ed. Viçosa, MG: Universidade Federal de Viçosa, 2005. 186p.

SCHINCKEL, A.P.; RICHERT, B.T., HERR, C.T. et al. Efeitos da ractopamina sobre o crescimento, a composição da carcaça e a qualidade dos suínos. In: CONFERÊNCIA INTERNACIONAL VIRTUAL SOBRE QUALIDADE DE CARNE SUÍNA, 2., 2001, Concórdia. Anais... Concórdia, 2001. p.324-335.

SEE, M.T.; ARMSTRONG, T.A.; WELDON, W.C. Effect of a ractopamine feeding program on growth performance and carcass composition in finishing pigs. Journal of Animal Science, v.82, p.2474-2480, 2004.

SELLE, P.H., RAVINDRAN, V. Microbial phytase in poultry nutrition. Animal Feed Science and Technology, v.135, p.1-41, 2006.

SEYNAEVE, M.; JANSSENS, G.; HESTA, M. et al. Effects of dietary $\mathrm{Ca} / \mathrm{P}$ ratio, $\mathrm{P}$ level and microbial phytase supplementation on nutrient digestibilities in growing pigs: precaecal, post-ileal and total tract disappearances of OM, $\mathrm{P}$ and Ca. Journal of Animal Physiology and Animal Nutrition, v.83, p.36-48, 2000

SHELTON, J.L.; SOUTHERN, L.L.; BIDNER, T.D. et al. Effects of microbial phytase on energy availability, and lipid and protein deposition in growing swine. Journal of Animal Science, v.81, p.2053-2062, 2003.

SHELTON, J.L.; SOUTHERN, L.L.; LeMIEUX, F.M. et al. Effects of microbial phytase, low calcium and phosphorus, and removing the dietary trace mineral premix on carcass traits, pork quality, plasma metabolites, and tissue mineral content in growing-finishing pigs. Journal of Animal Science, v.82, p.2630-2639, 2004.

SIMONS, P.C.M.; VERSTEEGH, H.A.J.; JONGBLOED, A.W et al. Improvement of phosphorus availability by microbial phytase in broilers and pigs. British Journal of Nutrition, v.64, p.525-540, 1990. 
STITES, C.R.; MCKEITH, F.K.; SINGH, S.D. et al. The effect of ractopamina hydrochloride on the carcass cutting yields of finishing swine. Journal of Animal Science, v.69, n.8, p.3094-3101, 1991.

TEIXEIRA, A.O.; LOPES, D.C.; GOMES, P.C. et al. Níveis de substituição do fosfato bicálcico pelo monobicálcico em dietas para suínos nas fases de crescimento e terminação. Revista Brasileira de Zootecnia, v.34, n.1, p.142-150, 2005.

UNIVERSIDADE FEDERAL DE VIÇOSA - UFV. Sistema para Análises Estatísticas e Genética - SAEG (Versão 8.0). Viçosa, MG: Universidade Federal de Viçosa, 1999. 142p.
XIAO, R.; XU, Z.; CHEN, H. Effects of ractopamine at different dietary protein levels on growth performance and carcass characteristics in finishing pigs. Animal Feed Science and Technology, v.79, p.119-127, 1999.

XIONG, Y.L.; GOWER, M.J.; LI, C. et al. Effect of dietary ractopamine on tenderness and postmortem protein degradation of pork muscle. Meat Science, v.73, p.600-604, 2006.

WILLIAMS, N.H.; CLINE, T.R.; SCHINCKEL, A.P. et al. The impact of ractopamine, energy intake, and dietary fat on finisher pig growth performance and carcass merit. Journal of Animal Science, v.72, p.3152-3162, 1994 